\title{
EFEITO DE EXTRATOS AQUOSOS DE PLANTAS ESPONTÂNEAS DO CERRADO SOBRE A GERMINAÇÃO DE TRÊS GRAMÍNEAS
}

\author{
Vlademir Natanael Frazão, Larissa da Luz Silva1*, Renata Del Carratore Carneiro² \\ ${ }^{1}$ Engenheiros Agrônomos, Universidade do Estado de Mato Grosso (UNEMAT), Campus de Nova Xavantina, Rua Prof. Dr. Renato \\ Figueiro Varella, $s / n$ - Nova Xavantina/MT - CEP:78600-000 \\ ${ }^{2}$ Professora Doutora, Departamento de Agronomia, Universidade do Estado de Mato Grosso (UNEMAT), Rua Prof. Dr. Renato Figueiro \\ Varella, s/n - Nova Xavantina/MT - CEP:78600-000 \\ *Autor para correspondência: Larissa da Luz Silva, larissaetebg@gmail.com
}

\begin{abstract}
RESUMO: Estudos demonstram que plantas do Cerrado apresentam efeito alelopático em espécies forrageiras. $O$ presente estudo teve como objetivo avaliar o efeito dos extratos de Vernonanthura ferruginea (Less.) H. Rob. e Cenostigma macrophyllum Tul. sobre a germinação de Brachiaria brizantha cv. Marandu, Panicum maximum cv. Tanzânia e Panicum maximum cv. Mombaça. Os ensaios foram conduzidos em esquema fatorial com delineamento inteiramente casualizados totalizando nove tratamentos e quatro repetições. Foram distribuídas 25 sementes, de cada forrageira, em caixas GerBox forradas com folhas de papel filtro e adicionado $10 \mathrm{ml}$ do extrato em seguida levadas à estufa. B. brizantha cv. Marandu apresentou os menores percentuais de germinação em relação aos outros tratamentos por sua vez $P$. maximum cv. Mombaça teve a germinação estimulada na presença do extrato de $V$. ferruginea. $O$ extrato aquoso de $C$. macrophyllum não apresentou alelopatia em nenhuma das gramíneas. Denota-se que a ocorrência desta planta esteja relacionada com outras características. Estudos em condições similares às do Cerrado devem ser realizados para avaliar se as espécies apresentam comportamento semelhante ao que ocorreu no presente trabalho.
\end{abstract}

PALAVRAS-CHAVE: Alelopatia; Pastagem; Brachiaria brizantha; Panicum maximum; Vernonanthura ferruginea (Less.) H. Rob; Cenostigma macrophyllum Tul; Caneleiro.

\section{EFFECT OF AQUEOUS EXTRACTS FROM SPONTANEOUS PLANTS IN THE CERRADO ON THE GERMINATION OF THREE GRASSES}

\begin{abstract}
Studies show that plants from Cerrado have allelopathic effect in forage species. The present study aimed to evaluate the effect of extracts of Vernonanthura ferruginea (Less.) H. Rob. And Cenostigna macrophyllum Tul. on germination of Brachiaria brizantha. cv. Marandu, Panicum maximum cv. Tanzania and Panicum maximum cv. Mombaça. The trials were conducted in factorial draft with completely randomized design with a total of nine treatments and four replications. Twenty-five (25) seeds were distributed, from each forage in Gerboxes lined with sheets of filter paper and added $10 \mathrm{ml}$ of the extract then they were taken to the greenhouse. B. brizantha cv. Marandu had the lowest percentage of germination when compared to other treatments, on the other hand $P$. maximum $\mathrm{cv}$. Mombaça had stimulated germination in the presence of the extract of V. ferruginea. The aqueous extract of $C$. macrophyllum did not present allelopathy in any of the grasses. Denotes that the occurrence of this plant is related to other characteristics. Studies on similar conditions to the Cerrado ones should be performed to assess whether the species present behavior similar to what occurred in the present work.
\end{abstract}

KEYWORDS: Allelopathy; Grassland; Brachiaria brizantha; Panicum maximum; Vernonanthura ferruginea (Less.) H. Rob; Cenostigma macrophyllum Tul; Caneleiro.

\section{INTRODUÇÃO}

O Brasil possui o maior rebanho comercial bovino do mundo (Poll et al., 2011) e essa particularidade foi essencial para eleva-lo, já na década passada, à condição de maior exportador de carne. Segundo levantamentos recentes do Instituto Brasileiro de geografia e Estatística - IBGE (2017), o plantel nacional atingiu a marca de 209,5 milhões de animais, com destaque para as raças zebuínas (Bos indicus) que compõe aproximadamente $80 \%$ do rebanho nacional.
A pecuária nacional está calcada em uma base de tríplice apoio constituída pela genética, pela pastagem e pelo manejo. Porém, uma peculiaridade marcante da pecuária brasileira é ter a produção de todo o seu rebanho a pasto e resíduos agrícolas, no caso dos confinamentos (mais utilizados na terminação do rebanho). Esse diferencial faz da pecuária nacional uma das de menor custo de produção, quando comparado aos grandes produtores e exportadores mundiais de carne. Assim o chamado "boi verde", criado a pasto, é sem dúvida 
o que assegura a competitividade e predominância do País no mercado de carnes (Poll et al., 2011).

O Centro-oeste brasileiro tem lugar de destaque na pecuária nacional, principalmente o estado de Mato Grosso (Guimarães et al., 2011) que detém o maior rebanho do País com 28,7 milhões de animais, equivalente a $13,7 \%$ do rebanho nacional (lbge, 2017). As forrageiras ocupam extensas áreas no estado, com predominâncias das gramíneas (Lima e Deminices, 2008). Dos seus 90,33 milhões de hectares de extensão territorial esta unidade da federação possui 25,8 milhões de hectares ocupados com pastagens (Imea, 2012).

Apesar de serem à base da pecuária nacional, as áreas de pastagens têm apresentado rápido e acentuado declínio em sua capacidade produtiva. Este cenário é reflexo de um gerenciamento deficiente do empreendimento e pelo manejo inadequado do sistema solo-planta, forrageira-animal em pastejo. Tais fatores contribuem para aumentar a deterioração nas áreas de pastagens, limitando e, em muitos casos, até inviabilizando a produção de carne e/ou leite em muitas regiões do país (Martha Junior e Vilela, 2002).

Decorre deste processo de degradação a ocorrência exacerbada de plantas espontâneas e/ou pioneiras (Dias Filho, 1990) que cressem juntamente com a pastagem interferindo no seu desenvolvimento e dificultando o acesso dos animais à forragem. Além de competir pela extração de água e nutrientes, as plantas espontâneas e/ou pioneiras possuem indícios de atividade alelopática - interferência química (Aires, 2004). A infestação por plantas dessa natureza, devido à sua agressividade de competição, reduz a produtividade das forrageiras, causam queda da capacidade de suporte da pastagem, aumentam o tempo de formação e/ou recuperação das forrageiras acarretando impactos econômicos para os pecuaristas (Embrapa, 2012).

A alelopatia ocorre através de interações bioquímicas, tanto inibitórias como estimulatórias, entre todos os tipos de plantas. A acumulação de substâncias com efeitos alelopáticos tem sido verificada em todos os órgãos vegetais, existindo uma tendência de maior acúmulo nas folhas, sendo que a liberação desses compostos pode ocorrer por exsudação radicular, lixiviação ou volatilização (Moreira et al., 2008).

As plantas infestantes são, sem dúvida, um dos principais problemas de ordem bio-econômica a impor limitações à produtividade e rentabilidade de atividades agrárias. Em áreas de pastagens essas plantas assumem papel relevante devido ao alto custo de controle, perdas de animais causadas por plantas tóxicas e também pela redução quantitativa e qualitativa das forrageiras. As plantas infestantes apresentam basicamente dois tipos de interferências em cultivos agrícolas (alelospolia e/ou alelopatia). Alelospolia é o tipo de interferência promovida pela competição por fatores como água, nutrientes e espaço físico. Por sua vez o mecanismo de alelopatia envolve a produção e subsequente liberação, para o ambiente, de substâncias químicas com atividade alelopática que iniba e/ou favoreça o desenvolvimento de outras plantas. Seja qual for o meio de interferência, a consequência desses processos é a redução da densidade e alteração do padrão da vegetação. (Souza Filho, 2012).

Estudos conduzidos com plantas do Cerrado demonstram que extratos aquosos de estruturas vegetais apresentam efeito alelopático no desenvolvimento de espécies alvo (Aires, 2004; Inoue et al., 2010; Moreira et al., 2008; Souza Filho et al., 1996).

Souza Filho (2012) relata que nas espécies de plantas mais agressivas do mundo tem sido observada atividade alelopática de alguma maneira, o que sugere que parte dessa agressividade esteja relacionada com essa característica. Ainda de acordo com o mesmo autor, este fenômeno tem sido reconhecido como um importante mecanismo ecológico, o qual influencia a dominância da vegetação, a sucessão de plantas, a formação de comunidades de plantas, no estabelecimento e produtividade em ecossistemas de pastagens cultivadas.

A espécie Vernonanthura ferruginea (Less.) $\mathrm{H}$. Rob, popularmente conhecida como "assa-peixe", "assa-peixe-do-pará", "assa-peixe-de-santana" (Apêndice) é uma das muitas espécies de plantas invasoras de pastagens. Com ampla distribuição geográfica ocorre em quase todo o território brasileiro. Norte (Amazonas, Tocantins), Nordeste (Maranhão, Piauí, Ceará, Paraíba, Pernambuco, Bahia, Sergipe), CentroOeste (Mato Grosso, Goiás, Distrito Federal, Mato Grosso do Sul), Sudeste (Minas Gerais, São Paulo), Sul (Rio Grande do Sul). Planta perene, de porte arbustivo, floresce de agosto a outubro com frutificação nos meses de novembro a março. Apresenta reprodução por sementes que se dispersam por aquênios, mas podendo também ocorrer em alguns casos por rizomas. Pouco exigente quanto à fertilidade do solo, plantas do gênero Vernonanthura spp. são comuns em áreas que ocorrem queimadas frequentes e/ou nos estágios iniciais de processo de regeneração, em solos de baixa fertilidade, essencialmente os arenosos, muito competitiva em solos de Cerrado, embora possam também ocorrer em outras condições de solo. (Alberguini e Yamashita, 2010; Soares e Almeida, 2012).

A espécie Cenostigma macrophyllum Tul. conhecida pelos nomes populares de "fava-do- 
campo", "fava-de-besouro", "canela-de-velho", "caneleiro", "caneleira" "catingueira" e "maraximbé" pertence à família Caesalpinaceae composta por 47 gêneros. O gênero Cenostigma Tul é constituído por quatro espécies sendo três endêmicas do Brasil, Cenostigma macrophyllum Tul., Cenostigma tocantinum Ducke, Cenostigma gardnerianum Tul. A única espécie que não é exclusivamente brasileira Cenostigma sclerophyllu que ocorre também no Chaco Paraguaio (Fapepi, 2006).

Plantas de Cenostigma macrophyllum são largamente distribuídas nos biomas Cerrado e Caatinga. Ocorre nos estados do Paraná, Mato Grosso do Sul, Mato Grosso, Tocantins, Goiás, Minas Gerais, Maranhão, Ceará, Bahia e Piauí (Lewis, 2020). De porte arbóreo arbustivo podem atingir até 20 metros de altura, com a superfície do caule provida de sulcos, dando-lhe 0 aspecto canelado ("canelas sobrepostas"), daí o nome popular de caneleiro e/ou caneleira.

Resistente ao fogo, rebrota facilmente após a ocorrência de queimadas ou quando roçada, germina sem dificuldade e apresenta desenvolvimento razoável. Com longo período de florescimento, de agosto a fevereiro, frutifica entre fevereiro a junho. As flores são amarelas, reunidas em inflorescências, suavemente perfumadas, com uma pétala interior mediana menor, lembrando uma orquídea, características que the atribuem um aspecto ornamental. Devido a estas características a espécie foi designada como árvore símbolo de Teresina, capital do estado do Piauí (Fapepi, 2006).

O objetivo deste trabalho foi avaliar a influência dos extratos aquosos preparados a partir de folhas verdes de Vernonanthura ferruginea (Less.) H. Rob. e Cenostigma macrophyllum Tul. (plantas doadoras) sobre a germinação de sementes de Brachiaria brizantha cv. Marandu, Panicum maximum cv. Tanzânia e Panicum maximum cv. Mombaça.

\section{MATERIAL E MÉTODOS}

O experimento foi conduzido no Laboratório de Solos da Universidade do Estado de Mato Grosso (UNEMAT), Campus de Nova Xavantina-MT, situado no Parque Nacional Mário Viana (Parque do Bacaba) entre as coordenadas $14^{\circ} 42^{\prime} 28,8^{\prime \prime} \mathrm{S}$ e $52^{\circ} 21^{\prime} 03,9^{\prime \prime}$ W, com altitude de $348,5 \mathrm{~m}$ (Ribeiro et al., 2011).

Para a obtenção dos extratos aquosos foram utilizadas folhas frescas de Vernonanthura ferruginea e Cenostigma. macrophyllum coletadas ao acaso. Após a coleta, 200 gramas de matéria verde foram trituradas em um litro de água destilada no liquidificador por três minutos, conforme Cruz et al. (2000), a fim de se obter o extrato bruto aquoso concentrado a $20 \%$ (peso/volume - p/v).

Os ensaios de germinação foram realizados em esquema fatorial com delineamento inteiramente casualizados (DIC) com nove tratamentos (Tabela 1) e quatro repetições totalizando 36 unidades amostrais (caixas GerBox). Estas foram previamente esterilizadas em uma solução de hipoclorito de sódio a $10 \%$ por 30 minutos, após este período foram secas e forradas com duas folhas de papel filtro, em seguida foram distribuídas 25 sementes de Brachiaria brizantha cv. Marandu, de Panicum maximum cv. Tanzânia e Panicum maximum cv. Mombaça em suas respectivas unidades amostrais (caixas GerBox previamente preparadas), adicionado $10 \mathrm{ml}$ do extrato bruto.

Tabela 1. Tratamentos realizados para avaliação de efeitos alelopáticos dos extratos aquosos de folhas de $V$. ferruginea e $C$. macrophyllum sobre germinação de sementes de $B$. brizantha cv. Marandu, $P$. maximum cv. e Tanzânia P. maximum cv. Mombaça, Nova Xavantina - MT.

\begin{tabular}{lccc}
\hline & \multicolumn{3}{c}{ Espécies doadoras } \\
\cline { 2 - 4 } & V. ferruginea & C. macrophyllum & Trat. Controle \\
\cline { 2 - 4 } & $\mathrm{T}_{1}$ & Tratamentos \\
\hline B. brizantha cv. Marandu & $\mathrm{T}_{4}$ & $\mathrm{~T}_{2}$ & $\mathrm{~T}_{3}$ \\
P. maximum cv. Tanzânia & $\mathrm{T}_{7}$ & $\mathrm{~T}_{5}$ & $\mathrm{~T}_{6}$ \\
P. maximum cv. Mombaça & $\mathrm{T}_{8}$ & $\mathrm{~T}_{9}$ \\
\hline
\end{tabular}

O tratamento controle recebeu o mesmo volume de água destilada, identificadas e levadas à estufa onde permaneceram por dez dias conforme Souza Filho et al. (2005), com temperatura controlada para $28^{\circ} \mathrm{C}$ com fotoperíodo contínuo (24 horas). A germinação das sementes exposta ao extrato bruto foi monitorada comparando-as com o tratamento controle.

Foi considerada germinada a semente que apresentou protrusão da radícula de $2 \mathrm{~mm}$ para fora do tegumento, com contagens diárias e eliminação das sementes germinadas conforme Souza Filho et al. (1996). Os dados obtidos foram submetidos a análise de variância pelo software estatístico ASSISTAT 7.6 beta, pelo teste de $\mathrm{F}$ e as médias comparas pelo teste de Tukey a $5 \%$ de probabilidade.

A germinação foi analisada sob dois aspectos: porcentagem de germinação e índice de velocidade de germinação. Este parâmetro foi monitorado por um período de dez dias, com contagens diárias e eliminação das sementes germinadas. $O$ índice de velocidade de germinação (IVG) foi calculado pela 
seguinte equação proposta por Maguire (1962, apud Oliveira et al., 2009).

$$
I V G=\frac{G 1}{T 1}+\frac{G 2}{T 2}+\frac{G 3}{T 3}+\cdots+\frac{G n}{T n}
$$

Em que: IVG é índice de velocidade de germinação; G1 até $G$ n é o número de plântulas germinadas ocorridas a cada dia; $T 1$ até $T n$ é o tempo em dias.

\section{RESULTADOS E DISCUSSÃO}

Os resultados dos bioensaios de germinação estão apresentados na Figura 1. A gramínea forrageira Brachiaria brizantha cv. Marandu, dentre as três cultivares avaliadas, foi a que apresentou os menores percentuais de germinação para todos os tratamentos conduzidos. O extrato aquoso de folhas de Vernonanthura ferruginea (assa-peixe) proporcionou redução média na ordem de $17 \%$ na germinação das sementes dessa gramínea em comparação ao tratamento controle.

Figura 1. Germinação de sementes de $B$. brizantha cv. Marandu, $P$. maximum cv. Tanzânia e $P$. maximum $\mathrm{cv}$. Mombaça submetidas aos extratos aquosos de folhas de $V$. ferruginea e $C$. macrophyllum. Nova Xavantina - MT.

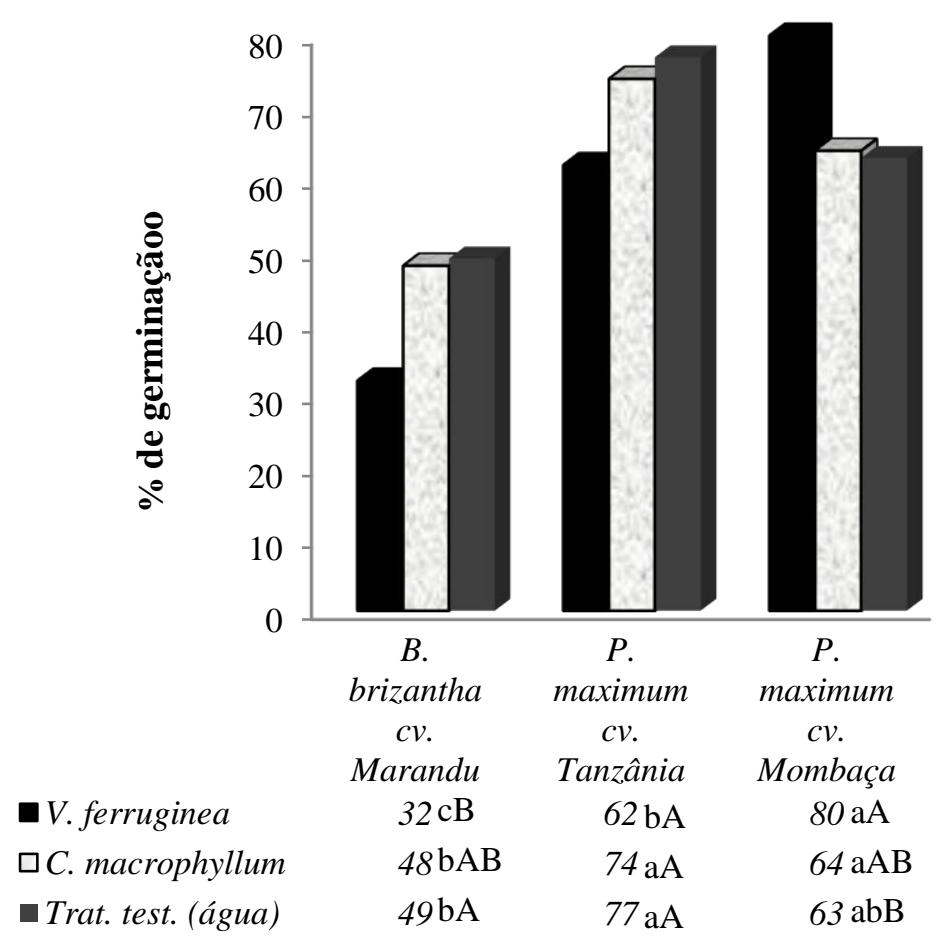

Para cada variável, médias seguidas pela mesma letra minúscula na linha e maiúscula na coluna, não diferem estatisticamente entre si pelo Teste de Tukey ao nível de $5 \%$ de probabilidade. CV\% $=15,47$.

Valores mais expressivos foram obtidos por Inoue et al. (2010), que avaliando o potencial alelopático de extratos hidroalcoólicos de Annona crassiflora (Araticum), constataram que os extratos aquosos provenientes das folhas dessa planta reduziram em mais de $50 \%$ a germinação das sementes de Brachiaria brizantha cv. Marandu. Por sua vez, Souza Filho (2006) relatou redução de $25 \%$ na germinação de Brachiaria brizantha cv. Marandu exposto ao efeito de extrato aquoso de folhas de capim-gengibre (Paspalum maritimum).

Os resultados do presente estudo, embora não sejam semelhantes, se correlacionam com os obtidos por Souza filho et al. (1996), que estudaram o efeito potencialmente alelopático do assa-peixe sobre a germinação de três gramíneas forrageiras do gênero Brachiaria spp., no qual a geminação de sementes de Brachiaria brizantha cv. Marandu também foi expressivamente inibida na presença do extrato da parte aérea dessa planta. Estes resultados levam a inferir que a alelopatia seja um dos fatores que favorecem a formação de estandes de Vernonanthura ferruginea em sistemas de pastagens cultivadas em áreas de Cerrado.

Para a gramínea Panicum maximum cv. Tanzânia não foram obtidos resultados, significativos quanto atuação alelopática dos extratos aquosos de ambas as espécies doadoras em relação ao tratamento controle (Figura 1). Porém, ainda que a redução de $15 \%$ constatada no presente estudo, devido à exposição ao extrato de Vernonanthura ferruginea, na germinação das sementes dessa forrageira não seja estatisticamente significativo para os parâmetros avaliados nesta pesquisa, tais resultados não devem ser desprezados. 
Alguns pesquisadores consideram que a inibição e/ou estimulo de $50 \%$ na germinação de sementes seria um padrão aceitável para avaliar o potencial alelopático de extratos vegetais em ensaios de alelopatia (Moreira et al., 2008; Souza Filho et al., 2005; Souza Filho, 2006), resultados dessa grandeza não foram encontrados no presente estudo.

Posto que o padrão mínimo de germinação estabelecido pela legislação vigente para a comercialização de sementes de gramíneas do gênero Panicum maximum é de $40 \%$ (Mapa, 2008). Do ponto de vista econômico e também agronômico, em condições de estabelecimento de pastagem, um decréscimo na germinação igual à verificada no presente estudo, não seria desejável, pois, acarretaria uma má formação do estande forrageiro, consequentemente favorecendo o surgimento e a competição de plantas espontâneas. Tal fato certamente favoreceria os processos de degradação da pastagem.

Resultado contrário ao de Brachiaria brizantha cv. Marandu e Panicum maximum cv. Tanzânia foi observado para as sementes de Panicum maximum cv. Mombaça em que a germinação foi estimulada na presença do extrato aquoso de Vernonanthura ferruginea. Houve acréscimo de $17 \%$ na média de sementes germinadas em relação ao tratamento que se utilizou somente água destilada (Figura 1), sendo esta diferença significativa ao nível de $5 \%$ de probabilidade $(p<0,05)$.

Efeito alelopático estimulatório também foi encontrado também por Cruz et al. (2000). Esses pesquisadores avaliando a atividade potencialmente alelopática de algumas espécies de plantas medicinais observaram que o extrato aquoso de capim limão (Cymbopogon citratus) na concentração de $15 \%(\mathrm{p} / \mathrm{v})$ estimulou a germinação de sementes de trigo.

Entretanto Aires (2004) estudando o potencial alelopático de plantas do Cerrado comprovou haver efeito inibitório dos extratos aquosos em concentrações crescentes obtidos de folhas de Caryocar brasiliense (pequi), Qualea parviflora (pau terra) e Eugenia dysinterica (cagaita) sobre a germinação de sementes capim gordura (Melinis minutiflora). Ainda de acordo com Aires (2004), mesmo que não significativamente, os extratos das três espécies estudadas promoveram um moderado acréscimo na germinabilidade de sementes de milho (Zea mays).

Moreira et al. (2008) avaliando o efeito do extrato metanólico obtidos a partir das folhas de pequi (Caryocar brasiliense) constataram a existência de potencial fitotóxico na germinação, desenvolvimento da raiz e parte aérea de Panicum maximum (capim-colonião) quando exposto a estes compostos.

A forma que o efeito alelopático atua, inibindo ou estimulando a germinação de sementes e/ou no desenvolvimento de plântulas de outras espécies vegetais intervêm na densidade de plantas de um agroecossistema, podendo a curto ou longo prazo alterar a composição botânica do mesmo (Cruz et al., 2000; Dias, 2010; Souza Filho e Alves, 1998; Souza Filho et al., 1996).

Não foi observada diferença significativa na germinação de nenhuma das três gramíneas submetidas ao extrato aquoso de folhas de Cenostigma macrophyllum em comparação ao tratamento controle (Figura 1). Embora a espécie Cenostigma macrophyllum seja objeto de recentes estudos a fim de se identificar potencialidades farmacológicas, nas linhas de pesquisa e banco/base de dados bibliográficos consultados para a elaboração deste trabalho não foram encontrados estudos que remetessem à alguma atividade alelopática dessa espécie.

Em presença dessas informações e dos resultados obtidos no presente estudo, denota-se que a espontaneidade do surgimento agressivo dessa espécie em áreas de pastagens cultivadas no Vale do Araguaia esteja relacionada à sua capacidade de adaptação aos fatores ambientais do Cerrado, assim como sua rusticidade e resistência a condições de estresse e/ou perturbações que eventualmente ocorrem no ambiente, a exemplo das queimadas (Lewis, 2020). Características estas que tornam plantas espontâneas e/ou pioneiras mais eficientes na absorção/interceptação de elementos do meio necessários para seu estabelecimento a exemplo dos nutrientes minerais, água e luminosidade (Souza Filho e Alves, 1998).

Com relação ao índice de velocidade de germinação (IVG), a sementes de $B$. brizantha cv. Marandu apresentou variações moderadas diante dos tratamentos submetidos, contudo não foram evidenciados efeitos alelopáticos significativos si, para as sementes $P$. maximum cv. Tanzânia e $P$. maximum cv. Mombaça, pelo Teste de Tukey ao nível de $5 \%$ de probabilidade para nenhuma das gramíneas estudadas, em relação ao tratamento controle (Figura 2). Segundo Aires (2004), o atraso na germinação poderia significar desvantagem para as sementes a campo, pois ficariam expostas a patógenos, a fatores ambientais e a predação por animais. Sobretudo, as plântulas originárias dessas sementes teriam que competir com plântulas já préestabelecidas e em crescimento. 
Figura 2. Índice de velocidade de germinação (IVG) em sementes de $B$. brizantha cv. Marandu, $P$. maximum cv. Tanzânia e $P$. maximum cv. Mombaça submetidas aos extratos aquosos de folhas de $V$. ferruginea e C. macrophyllum. Nova Xavantina - MT.

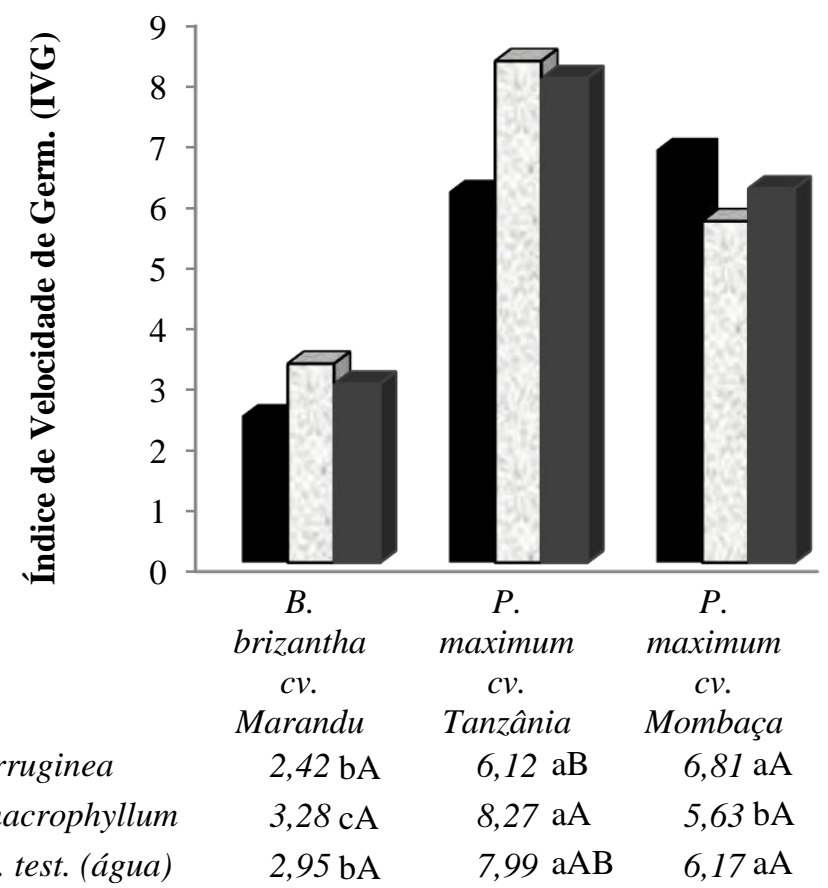

Para cada variável, médias seguidas pela mesma letra minúscula na linha e maiúscula na coluna, não diferem estatisticamente entre si pelo Teste de Tukey ao nível de $5 \%$ de probabilidade. CV\% $=19,34$.

Entre as forrageiras Brachiaria brizantha cv. Marandu e Panicum maximum cv. Tanzânia foi observado comportamento semelhante. Tiveram seu IVG ligeiramente inibido na presença do extrato de Vernonanthura ferruginea. Entretanto, na presença de Cenostigma macrophyllum, foi notado um pequeno favorecimento para ambas (Figura 2).

Por sua vez Panicum maximum cv. Mombaça manifestou comportamento oposto, sendo estimulado na presença de Vernonanthura ferruginea e inibido quando submetido ao extrato de Cenostigma macrophyllum. Inoue et al. (2010); Souza filho et al. (1996) estudaram o comportamento de sementes de Brachiaria brizantha submetidas a extrato de folhas assa-peixe, e atribuíram a redução da velocidade de germinação dessa gramínea ao efeito alelopático dessas plantas do Cerrado.

Segundo Inoue et al. (2010), um composto químico pode apresentar comportamento distinto para espécies diferentes, ou seja, num mesmo ambiente ocasionar efeito alelopático a algumas espécies e em outras não. Goldfarb et al. (2009); Rezende et al. (2012), complementam que os compostos potencialmente alelopáticos podem, dependendo da concentração destes no ambiente, causarem efeitos estimulantes e/ou inibitórios.

Moreira et al. (2008) constataram respostas diferenciadas da atividade alelopática dos extratos de C. brasiliense sobre o desenvolvimento de Panicum maximum, tanto para concentrações diferentes, como também em relação ao solvente utilizado para o fracionamento do extrato bruto. Aires et al., (2004), relataram haver alteração da atividade alelopática dos extratos de Solanum lycocarpum (lobeira, fruta de lobo) na germinação Sesamum indicum (gergelim), havendo a inibição da germinação em substrato solo e não ocorrendo o mesmo em substrato papel filtro. Os resultados obtidos no presente estudo apresentam aspectos agronômicos e também ecológicos importantes. Posto que, a condução de sistemas pastoris não está isenta, nem se deve ter este objetivo, da ocorrência de plantas naturais do ecossistema em que está inserido e que a concomitância destas com a forrageira pode ser favorável e/ou prejudicial. O conhecimento da biologia e/ou comportamento dessas espécies faz-se necessário para que o manejo e a condução desses sistemas ocorram de forma menos impactante possível.

Ensaios conduzidos em laboratórios com a utilização de extratos aquosos de folhas ou de outras estruturas vegetais visando avaliar, sob condições controladas, a atividade alelopática destes compostos na germinação de sementes ou no desenvolvimento inicial de plântulas é uma metodologia frequentemente utilizada em estudos de alelopatia em plantas. Visto que estudos dessa natureza são relativamente simples de serem conduzidos, além de fornecerem resultados rápidos e de fácil mensuração, germina ou não, e sugere-se então que o resultado é devido à atividade 
potencialmente alelopática dos extratos (Aires, 2004; Souza Filho et al., 2010).

Desta forma, o extrato aquoso de folhas de Vernonanthura ferruginea inibiu a germinação das sementes Brachiaria brizantha cv. Marandu; a germinação das sementes de Panicum maximum cv. Mombaça foi estimulada na presença do extrato aquoso de Vernonanthura ferrugínea, a gramínea Panicum maximum cv. Tanzânia não evidenciou resultados, significativos estatisticamente quanto atuação alelopática dos extratos aquosos de Vernonanthura ferruginea e Cenostigma macrophyllum, o extrato aquoso de Cenostigma macrophyllum não apresentou atividade alelopática na germinação em nenhuma das três gramíneas estudadas e os extratos aquosos de ambas as espécies estudadas não influenciaram significativamente (inibiram ou estimularam) a velocidade de germinação das gramíneas avaliadas.

Ressalta-se aqui, existir a necessidade de que estudos futuros sejam realizados a fim de verificar se em condições similares ao do ambiente natural (Cerrado) os extratos aquosos de Vernonanthura ferruginea e C. macrophyllum manifesta-se da mesma forma que ocorram no presente trabalho.

\section{REFERÊNCIAS}

Aires, S. S.; Ferreira, A., G.; Borghetti, F. Efeito alelopático de folhas e frutos de Solanum lycocarpum A. St.-Hil. (Solanaceae) na germinação e crescimento de Sesamun indicum L. (Pedaliaceae) em solo sob três temperaturas. Acta Botanica Brasilica, 2004, 19, 2, 401-406.

Alberguini, A. L.; Yamashita, O. M. Profundidade de semeadura e presença de palha afetam a emergência de plântulas de Vernonia ferruginea. Planta Daninha, 2010, 28, 1005-1013.

Cruz, M.E.S.; Nozaki, M.H.; Batista, M.A. Plantas medicinais e alelopatia. Biotecnologia, Ciência e Desenvolvimento, 2000, 15, 28-34. http://www.biotecnologia.com.br/revista/bio15/planta s.pdf.

Dias Filho, M. B. Plantas invasoras em pastagens cultivadas da Amazônia: estratégias de manejo e controle. Belém: EMBRAPA-CPATU. 1990. 103p.

Embrapa, Empresa Brasileira de Pesquisa Agropecuária. Livro identifica plantas daninhas em pastagens dos cerrados. 2012. http: //www. embrapa. br/imprensa/noticias/2007/agosto/3a-semana/livroidentifica-plantas-daninhas-em-pastagem-doscerrados/.
Goldfarb, M.; Pimentel, L. W.; Pimentel N. W. Alelopatia: relações nos agroecossistemas. Tecnologia e Ciência Agropecuária, 2009, 3, 1, 2328.

Guimarães, S. L.; Bomfim-Silva, E. M.; Polizel, A. C.; Campos, D. T. S. Produção de capim-marandu inoculado com Azospirillum spp. Enciclopédia Biosfera, 2011, 7, 13, 819-825.

Inoue, M. H.; Santana, D. C.; Souza Filho, A. P. S.; Possamai, A. C. S.; Silva, L. E.; Pereira, M. J. B.; Pereira, K. M. Potencial alelopático de Annona crassiflora: efeitos sobre plantas daninhas. Planta Daninha, 2010, 28, 3, 489-498.

IBGE, Instituto Brasileiro de Geografia e Estatística. Produção da Pecuária Municipal. v. 38. Rio de Janeiro: IBGE, 2017. 65p.

IMEA, Instituto Mato-Grossense de Economia Agropecuária. Bovinocultura mato-grossense: caracterização da bovinocultura no estado de mato grosso.

2012. http://imea.com.br/upload/caracterizacaobovinocultu ra.pdf.

Lewis, G.P. Cenostigma in Lista de Espécies da Flora do Brasil. Jardim Botânico do Rio de Janeiro. 2020. https://www.gbif.org/pt/species/157525913. Acesso em: 24 Abr. 2020.

Lima, E.S.; Deminicis, B.B. Produção e composição química de cultivares de capim elefante. PUBVET, 2008, 2, 14,1-6.

MAPA, Ministério da Agricultura, Pecuária e Abastecimento. Instrução Normativa nํㅜ 30, de 21 de maio de 2008. Estabelece normas e padrões para produção e comercialização de sementes de espécies forrageiras de clima tropical. 2008. http://www.lex.com.br/doc_1267625_INSTRUCAO NORMATIVA_N_30_DE_21_DE_MAIO_DE_2008.a spx.

Martha Junior, G. B. E Vilela, L. Pastagens no cerrado: baixa produtividade pelo uso limitado de fertilizantes. Documentos 50. Planaltina: Embrapa Cerrados, 2002.232 . http://www.infoteca.cnptia.embrapa.br/handle/doc/56 6479.

Moreira, P. F. S.; Souza, D. R.; Terrones, M. G. H. Avaliação do potencial alelopático do extrato metabólico obtido de folhas de Caryocar brasiliense $C A M B$. (pequi) na inibição do desenvolvimento da raiz em sementes de Panicum maximum. Bioscience 
$\begin{array}{lllll}\text { jornal, } 2008 . & 24, & 3, & \text { 74-79. }\end{array}$ http://www.seer.ufu.br/index.php/biosciencejournal/a rticle/download/6850/4538.

FAPEPI, Fundo de Amparo à Pesquisa do Estado do Piauí. NPPM e LPN comprovam propriedades terapêuticas do caneleiro. Sapiência, 2006, 3, 10, 5.

Oliveira, A., Martins, G., Silva, R., Vieira, H. Testes de vigor em sementes baseados no desempenho de plântulas. Inter Science Place, 2009, 1, 4, 1-21.

Poll, H.; Vencato, A. Z.; Kist, B. B.; Santos, C.; Reetz, E. R.; Beling, R. R. Anuário brasileiro da pecuária 2011. Santa Cruz do Sul: Editora Santa Cruz do Sul. 2011. $128 \mathrm{p}$.

Rezende, C. P.; Pinto, J. C.; Evangelista, A. R.; Santos, I. P. A. Alelopatia e suas interações na formação e manejo de pastagens. 2012. http://www.editora.ufla.br/_adm/upload/boletim/bol_5 4.pdf. Acesso em: 24 Jun. 2020.

Ribeiro, M; Vitorino, C; Farias, J.; Portela, A.; Braga, E. Levantamento florístico e fitossociológico em cerrado rupestre e cerrado típico contíguos do Parque do Bacaba. 2008. http://www2.unemat.br/prppg/jornada2008/resumos workshop/PG_Expandido_00334.pdf. Acesso em: 24 Jun. 2020.

Soares, P.N., Almeida, G. Vernonanthura in Lista de Espécies da Flora do Brasil. 2012. http://floradobrasil.jbrj.gov.br/2012/FB027446.

Acesso em: 24 Abr. 2020.

Souza Filho, A. P. S. Alelopatia e as plantas daninhas da amazônia. 2012. http://sbcpd.org/portal/images/stories/downloads/2si mposio/alelopatia.pdf. Acesso em: 24 Abr. 2020.

Souza Filho, A. P. S.; Rodriguees, L. R. A.; Rodrigues, T. J. D. Efeito de extratos aquosos de assa-peixe sobre germinação de três espécies de braquiária. Planta Daninha, 1996, 14, 2, 93-101.

Souza Filho, A. P. S.; Alves, S. de M. Alelopatia em ecossistema de pastagem cultivada. Belém: Embrapa-CPATU, $1998 . \quad 72 p . \quad h t t p:$ https://www.bibliotecaagptea.org.br/agricultura/defes a/livros/ALELOPATIA.pdf. Acesso em: 24 Jun. 2020.

Souza Filho, A. P. S. Interferência Potencialmente Alelopática Do Capim-Gengibre (Paspalum maritimum) em áreas de pastagens cultivadas.

Planta daninha, 2006, 24, 3, 451-456.
Souza Filho, A.P.S.; Guilhon, G.M.S.P.; Santos, L.S. Metodologias empregadas em estudos de avaliação da atividade alelopática em condições de laboratório: revisão crítica.Planta daninha, 2010, 28, 3, 689-697.

Souza Filho, A.P.S.; Pereira, A.A.G.; Bayma, J.C. Aleloquímico produzido pela gramínea forrageira Brachiaria humidicola. Planta daninha, 2005, 23, 1, 25-32. 